\title{
Implikatur dalam Lawakan Komika Abdur pada Acara Stand Up Comedy
}

\author{
The Implicature of a Comic Abdur's Jokes \\ on "Stand Up Comedy" Show
}

\author{
Elsya Rahmi \\ Tressyalina \\ Jurusan Bahasa dan Sastra Indonesia dan Daerah, \\ Fakultas Bahasa dan Seni, Universitas Negeri Padang, Padang \\ elsyarahmi300799@gmail.com
}

Riwayat Artikel: 19 Mei 2020; Diterima 12 Juni 2020; Diterbitkan 30 Juni 2020

\begin{abstract}
ABSTRAK
Lawakan komika Abdur pada acara Stand Up Comedy tersebut mengandung implikatur. Kajian pragmatik mengenai implikatur dalam lawakan komika Abdur pada acara Stand Up Comedy di dalam penelitian ini menggunakan teori Grice dengan adanya 2 jenis implikatur, yakni: (1) implikatur konvensional dan (2) implikatur nonkonvensional atau implikatur percakapan. Penelitian ini menggunakan metode deskriptif kualitatif. Sumber data pada penelitian ini adalah tuturan komika Abdur pada acara Stand Up Comedy yang diperoleh melalui Youtube. Tujuan penelitian ini adalah untuk mendeskripsikan implikatur yang terdapat dalam lawakan komika Abdur pada acara Stand Up Comedy dan jenis implikatur yang terdapat dalam lawakan tersebut. Teknik pengumpulan data penelitian dilakukan dengan teknik simak dan catat, sedangkan analisis data melalui langkahidentifikasi data, reduksi data, klasifikasi data, dan interpretasi data. Hasil penelitian sebagai berikut. (1) terdapat implikatur dalamlawakan Abdur pada acara Stand Up Comedy dan (2) ada 11 implikatur konvensional dalam lawakan Abdur pada acara Stand Up Comedy dan tidak ada implikatur nonkonvensional dalam lawakan tersebut.
\end{abstract}

Kata Kunci: Implikatur, lawakan, stand up comedy

\begin{abstract}
The Abdur'sjokes on the StandUp Comedy show contains implicature. Thispragmaticstudy about the implicature of a comic Abdur's jokes on Stand Up Comedy Show uses Grice'stheory in the presence of 2 types of implicature, namely: (1) conventional implicature and (2) non-conventional impicature or conversational implicature. This research uses descriptive qualitative method. The source of the research data is the Abdur's speech on the Stand Up Comedy show obtained through YouTube. The purpose of this study is to describe the implicature of a comic Abdur'sjokes on Stand Up Comedy show. The data are collected by listening and note taking techniques. The data analysis steps
\end{abstract}


include data identification, data reduction, data classification, and interpretation. The results of this study are as follows. (1) there are implicature of a comic Abdur's Jokes on Stand Up Comedy Show and (2) there are 11 conventional implicature of a comic Abdur's Jokes on Stand Up Comedy show and there is not non-conventional implicature.

Keywords: Implicature, jokes, stand up comedy

\section{PENDAHULUAN}

Salah satu cabang ilmu bahasa yang membahas atau mempelajari bahasa secara eksternal adalah pragmatik. Pragmatik merupakan salah satu ilmu dalam bidang linguistik. Pragmatik berkaitan dengan hubungan antara bentuk-bentuk bahasa dan pengguna bentuk- bentuk itu (Yule, 1996: 4). Ilmu dalampragmatik digunakanuntuk menyampaikan informasi kepada orang lain.

Ada berbagai macam cara yang bisa dilakukan dalam berkomunikasi dengan maksud menyampaikan informasi kepada komunikan. Secara umum penyampaian informasi tersebut dilakukan secara langsung maupun tidak langsung. Nurifa, Tressyalina, \& Noveria (2018:242) berpendapat bahwa tindak tutur langsung adalah tuturan yang sesuai dengan modus kalimatnya. Sedangkan tindak tutur tidak langsung adalah tuturan yang berbeda dengan modus kalimatnya, maka maksud dari tindak tutur tidak langsung dapat beragam dan tergantung pada konteksnya.

Komunikasi yang dilakukan oleh komunikator dan komunikan dikatakan berhasil apabila pesan yang ingin disampaikan mampu dipahami oleh komunikan. Dalam memahami maksud tuturan, komunikan perlu memiliki pengetahuan yang sama mengenai apa yang dituturkan. Tidak jarang, sebelum menyampaikan informasi yang hendak disampaikan, komunikator akan memberikan beberapa kalimat sebagai pengantar sebelum ia menyampaikan informasi. Selain itu, untuk memahami maksud dari tuturan seseorang, dapat dipelajari melalui implikatur.

Implikatur merupakan kajian pragmatik yang mengandung sesuatu yang diimplisitkan. Hal yang dipelajari dalam implikatur adalah perbedaan yang diucapkan oleh komunikator dan apa yang diimplisitkan. Ada dua jenis implikatur yang dikemukakan oleh Grice, yaitu: (1) implikatur konvensional dan (2) implikatur nonkonvensional atau implikatur percakapan. Implikatur nonkonvensional atau percakapan terjadi karena adanya pelanggaran prinsip kerjasama. Hal ini didukung oleh pendapat Budiyanto (2009) bahwa implikatur konvensional berkaitan dengan makna bentuk-bentuk linguistik, sedangkan implikatur nonkonvensional berkaitan dengan prinsip-prinsip pertuturan.

Komunikasi yang dilakukan tidak selalu dalam situasi serius. Komunikasi yang terjadi dapat disisipi humor meskipun hal yang disampaikan itu termasuk hal yang serius. Tidak jarang seseorang menyampaikan permintaan ataupun kritikannya disisipi humor. Seseorang yang sering membawakan lawakan atau humor tersebut adalah komika asal Larantuka, Flores, Nusa Tenggara Timur yang bernama Abdur Arsyad. Ia termasuk komika yang sering menyampaikan kritiknya melalui berbagai macam acara, termasuk Stand Up Comedy. Acara Stand Up Comedy tidak hanya memberikan hiburan atau lawakan 
kepada penonton, namun terdapat informasi tersembunyi atau kritikan yang disampaikan oleh komika. Kritikan tersebut disampaikan dengan teknik cerita yang telah disusun hingga dapat membuat penonton tertawa. Tuturan dengan maksud yang diimplikasikan oleh komika mengandung implikatur.

Dalam membawakan lawakannya, komika mengandalkan bahasa dan teknik bercerita. Penonton harus memahami cerita yang disampaikan agar tahu kelucuan lawakan tersebut. Bagian yang terlucu disebut dengan punch line atau bagian yang mengejutkan bagi penonton sehingga memberikan efek lucu.

Penelitian mengenai implikatur penting untuk dipelajari. Hal tersebut dikarenakankajianini menarik untuk diteliti. Dengan adanya maksud tuturan yang diimplisitkan akan membuat mitra tutur atau komunikan memiliki praanggapan mengenai tuturan penutur.

Berkaitan dengan pentingnya penelitian mengenai implikatur, beberapa penelitian telah dilakukan oleh peneliti sebelumnya. Wijayanti (2016) menyimpulkan terdapat implikatur pada lawakan Abdur pada acara Stand Up Comedy Indonesia (SUCI4), yakni mengakui kekurangan pribadi, keinginannya agar pemerintah memberikan perhatiannya di Indonesia Timur, dan Abdur juga mengkritik aturan dari pemerintah. Selain itu, Innanda \& Hamzah (2017) mengkaji implikatur percakapan dalam interaksi antara penjual dan pembeli.

Andryanto, Andayani, \& Rohmadi (2014) melakukan analisis pada tayangan Sketsa di Trans TV. Hasilnya adalah terdapat implikatur konvensional dan nonkonvensional pada tayangan tersebut. Selain itu, Handayani, Sumawarti, \& Suhita (2014) mengkaji implikatur percakapan dalam acara Mata Najwa. Hasil penelitiannya adalah ditemukannya 318 tuturan yang berimplikatur. Lain halnya dengan hasil penelitian yang dilakukan oleh Alfia, Rohmadi \& Purwadi (2014) yang menyimpulkan bahwa adanya pelanggaran prinsip kesantunan dan implikatur pada acara Talk Show komedi menjadikan acara tersebut menjadi lebih menarik, lebih hidup, dan lebih mengesankan.

Wahyuningsih \& Rafli (2017) mengkaji implikatur percakapan dalam Stand Up Comedy 4 dengan hasil penelitian berupa terdapat dua jenis implikatur, yaitu: implikatur konvensional dan implikatur, tiga sifat implikatur yang terdiri atas daya batal, daya pisah, dan daya kalkulabilitas. Tidak hanya itu, terdapat maksim kerja sama, maksim kuantitatif, maksim kualitatif, maksim cara, dan maksim relevansi pada acara tersebut. Tidak hanya itu, Nugraheni (2011) melakukan analisis mengenai implikatur percakapan. Ia menyimpulkan bahwa implikatur percakapan terjadi akibat adanyapelanggaran maksim. Pendapat ini didukung oleh Lubis (2015), ia menganalisis implikatur yang terdapat dalam acara Indonesia Lanyers Club. Ia menemukan bahwa terdapat 4 jenis pelanggaran maksim pada acara tersebut, yakni maksim kuantitas, maksim kuantitas, maksim cara, dan maksim relevansi. Ia juga menemukan bahwa tipe pelanggaran maksim yang dominan pada acara tersebut adalah pelanggaran maksim kuantitas. Alasan adanya pelanggaran maksim kuantitas adalah untuk menunjukkan rasa sakit dan inti masalah kepada penonton. Tidak hanya itu, tujuan untuk melindungi rasa malu juga menjadi alasan timbulnya pelanggaran maksim pada acara tersebut. Temuan lain pada penelitian yang 
dilakukan oleh Lubis adalah adanya pelanggaran maksim yang bertujuan untuk membela suatu kelompok tertentu serta menyalahkan pemerintah atas suatu hal yang terjadi.

Sari \& Litbagay (2019) meneliti mengenai implikatur di dalam dialog atau percakapan film yang berjudul 500 days of Summer. Ia menemukan ada empat jenis implikatur yang terdapat pada film tersebut. Implikatur tersebut adalah implikatur percakapan, implikatur skala, implikatur partikular dan implikatur konvensional. Pada umumnya, implikatur di dalam film tersebut didominasi oleh impikatur percakapan atau implikatur nonkonvensional.

Penelitian mengenai implikatur dalam lawakan Abdur pada acara Stand Up Comedy layak untuk diteliti. Cerita yang disampaikan oleh komika membuat penonton tertawa sebagai hiburan, namun makna yang diimplisitkan adalah hal yang serius.

Abdur dalam salah satu acara Stand Up Comedy yang digelar pada tanggal 7 November 2019 di Discovery Hotel dalam acara Malam Keakraban Team Commercial Ethical Dexa Medica 2019 membawakan cerita lucu yang mengandung implikatur. Dalam penelitian ini, akan dibahas mengenai bagaimana implikatur dalam tuturan Abdur pada acara tersebut dan jenis implikatur apa yang digunakan sesuai dengan teori Grice.

\section{METODE}

Jenis penelitian ini adalah penelitian deskriptif kualitatif. Sumber data penelitian ini adalah tuturan komika Abdur pada acara Stand Up Comedy yang diperoleh melalui rekaman video yang diunggah di YouTube. Data penelitian ini adalah tuturan komika Abdur pada acara Stand Up Comedy yang mengandung implikatur. Data dikumpulkan dengan menggunakan teknik simak dan catat. Peneliti menyimak tuturan Abdur pada acara Stand Up Comedy. Proses tersebut dilakukan secara berulang-ulang. Kemudian peneliti mencatat atau mentranskripsikan tuturan Abdur tersebut ke dalam bentuk tulisan. Hal ini akan memudahkan peneliti untuk menganalisis data tersebut. Instrumen penelitiannya adalah peneliti sendiri dengan pemahaman mengenai implikatur.

Data yang telah terkumpul dianalisis dengan langkah sebagai berikut. (1) mengidentifikasi data untuk menentukan tuturan atau data yang mengandung implikatur, (2) mereduksi data yang dilakukan dengan cara mereduksi data yang tidak mengandung implikatur, (3) mengklasifikasi data yang dilakukan dengan cara mengklasifikasikan tuturan yang termasuk implikatur konvensional dan implikatur nonkonvensional atau implikatur percakapan, dan (4) menginterpretasi data, yakni data yang mengandung implikatur konvensional dan implikatur nonkonvensional atau percakapan tersebut dianalisis dengan cara menafsirkan maksud atau makna yang diimplisitkan oleh komika Abdur pada acaraStandUpComedy. 


\section{HASIL DAN PEMBAHASAN}

Secara ringkas, berdasarkan analisis data yang dilakukan terhadap lawakan komika Abdur pada acara Stand Up Comedy, ditemukan dua hal berikut. (1) terdapat implikatur dalam lawakan komika Abdur pada acara Stand Up Comedy dan (2) implikatur konvensional yang terkandung dalam lawakan komika Abdur pada acara Stand Up Comedy tersebut berjumlah 11, sedangkan dalam lawakan tersebut tidak mengandung implikatur nonkonvensioanal atau percakapan.

\section{Konsep Implikatur Konvensional dan Implikatur Konvensional}

Implikatur berdasarkan teori Grice terdiri atas implikatur konvensional dan implikatur nonkonvensional. Adanya implikatur dalam tuturan dapat dilihat berdasarkan makna yang diimplisitkan oleh penutur di dalam tuturannya.

Hasanah (2017) berpendapat bahwa tuturan yang memiliki makna implikatur tidak dilihat dari makna tertulis atau makna yang sebenarnya, melainkan makna yang terbentuk dari persepsi atau anggapan mitra tuturatau pendengarnya. Pendapat tersebut selaras dengan pendapat Nugraheni (2010) yang menyimpulkan bahwa kajian pragmatik mengenai implikatur merupakan kajian yang membahas maksud atau makna dari suatu tuturan yang tersirat, dimaksudkan atau diartikan oleh mitra tutur melalui suatu percakapan.

Wahyuningsih \& Rafli (2017) berpendapat bahwa implikatur konvensional itu tidak harus terjadi dalam percakapan. Tidak hanya itu, untuk menginterpretasikan implikatur konvensional tersebut tidak memerlukan konteks yang khusus. Lain halnya dengan pendapat Rosyida \& Asror (2019) bahwa konteks tuturan harus diketahui terlebih dahulu untuk memahami implikatur dalam suatu tindak tutur. Berdasarkan analisis yang dilakukan, berikut ini pembahasan mengenai implikatur dalam lawakan komika Abdur pada acara Stand Up Comedy.

\section{Implikatur Konvensional}

Lawakan komika Abdur pada acara Stand Up Comedy di Discovery Hotel tersebut mengandung beberapa implikatur konvensional. Ada 11 implikatur konvensional pada lawakan Abdur tersebut. Berikut ini data implikatur konvensional yang terdapat dalam lawakan komika Abdurpada acara StandUpComedy.

(1) Halo. Selamat malam semuanya. Luar Biasa. Hitam-hitam semuanya. Terang sekali ya lampunya, ya. Mentang-mentang saya orang Timur, seolah-olah kayak ngasib tahu ei ini listrik. Ini listrik, gitu. Jangan gitu dong, bang.

"Mentang-mentang saya orang Timur, seolah-olah kayak ngasib tahu ei ini listrik. Ini listrik, gitu." mengandung makna yang diimplisitkan atau tersirat. Kutipan tersebut mengandung implikatur konvensional bahwa di daerah Timur tersebut masih sulit mendapatkan akses listrik. Tidak hanya itu, lampu 
yang mereka pasang di rumah tidak terlalu terang. Makna yang diimplisitkan tersebut dapat dilihat melalui pernyataan sebelumnya bahwa "Terang sekali ya lampunya, ya."

(2) Saya anak ketiga dari 5 bersaudara. Bapak saya tidak ikut KB. Karna Bapak saya pikir kalau dua anak saja cukup, apalagi 5 anak. Cukup sengsara hidup kami.

Kalimat dalam lawakan tersebut termasuk ke dalam implikatur konvensional. Pernyataan tersebut tidak hanya menginformasikan bahwa ia merupakan anak ketiga dari lima bersaudara dan informasi bahwa Bapaknya tidak mengikuti program KB (Keluarga Berencana). Namun, ia ingin menyampaikan bahwa apabila Bapaknya hanya memiliki dua orang anak, hidup mereka akan sengsara.

(3) Sebenarnya bukan karena orang Timur itu tidak paham KB. Bukan. Kami itu paham itu. Kami mengerti masalah KB. Masalahnya adalah kondisi geografis di sana yang tidak memungkinkan untuk seluruh pekerjaan rumah dikerjakan oleh hanya dua orang anak. Wuih tidak mungkin. Pekerjaan rumah di sana itu banyak dan jauh-jauh. Potong rumput, ambil air, jaga ternak, cari ikan, cari masalah...banyak. Pekerjaannya banyak. Banyak sekali.

Pada data (3) lawakan Abdurtersebutmampu dimengerti oleh penonton karena Abdur menyampaikan skema mengenai geografis di daerahnya. Implikatur konvensional yang terdapat di dalam lawakan tersebut adalah makna tersembunyi yang diimplisitkan bahwa aktivitas mereka di Indonesia Timur itu jaraknya jauh antara satu aktivitas sehari-hari dengan aktivitas yang lain. Tidak hanya itu, makna lain yang diimplisitkan adalah di rumah mereka tidak mengalir air bersih untuk kebutuhan sehari-hari. Hal itu dapat dilihat di dalam pernyataanya "Potong rumput, ambil air, jaga ternak, cari ikan, cari masalah... banyak." Pernyataan tersebut juga dapat dimaknai sebagai kritikan terhadap pemerintah mengenai sulitnya air bersih di daerah tersebut. Pernyataan "Pekerjaannya banyak. Banyak sekali." merupakan penekanan bahwa pekerjaan sehari-hari yang dilakukan tidak dapat dikerjakan oleh keluarga yang hanya memiliki dua orang anak.

(4) Pak, mohon maaf. Kalau akar pinang itu bagus untuk malaria, kenapa di Indonesia Timur itu banyak orang yang mati karna malaria, ya? Kalau kami tahu akar pinang bagus untuk malaria, jangankan pohon pinang, ya. Jangankan akar pinang, akar kelapa juga kami cabut dari pohon faktornya. Kami cabut.

Berdasarkan data (4) makna yang ingin disampaikan adalah banyak orang Timur yang meninggal karena malaria. Hal yang diimplisitkan adalah meskipun malaria merupakan penyakityang dapat ditanganiatau disembuhkan dengan dirawat di Rumah Sakit dan mendapatkan penanganan oleh tenaga medis, namun di Indonesia Timur justru banyak yang meninggal karena malaria karena akses menuju rumah sakit itu jauh. Sebelumnya, komika Abdur 
dalam tuturannya telah menyampaikan mengenai kondisi geografis di Indonesia Timur. Lawakan tersebut juga bermakna bahwa jika orang Timur tahu akar pinang dapat mengobati malaria, tidak akan banyak terjadi kasus orang Timur meninggal karena malaria tersebut.

Bagian punch line pada lawakan tersebut adalah "Jangankan pohon pinang, ya. Jangankan akar pinang, akar kelapa juga kami cabut dari pohon faktornya. Kami cabut." Penonton mengetahui bahwa pohon faktor merupakan istilah yang digunakan dalam Matematika, sehingga bagian punch line tersebut membuat lawakan Abdur menjadilucu.

(5) Tapi ternyata setelah saya coba teliti di daerah saya. Sebenarnya itu begini, buat mungkin yang mungkin masih beranggapan kalau di Indonesia Timur banyak obat herbal, itu sebenarnya begini. Di Indonesia Timur, termasuk di desa saya, terkhususnya di desa saya itu. Kami itu rumah sakit tidak ada. Ada di kabupaten. Di desa saya tidak ada rumah sakit. Apotik tidak ada. Jadi karna jangkauan kita untuk dapat obat yang bagus-bagus itu susah. Maka masyarakat di sana itu berimprovisasi dengan kekayaan alam. Itulah yang terjadi.

Data (5) dituturkan untuk menjelaskan penyebab timbulnya anggapan orang lain bahwa di Indonesia Timur, banyak ditemukan obat-obat herbal. Meskipun demikian, makna implisit yang sebenarnya ingin disampaikan adalah di desanya tidak terdapat rumah sakit dan apotek. Lawakan tersebut termasuk kritikan bahwa layanan medis tidak ada di desanya, sehingga warga di sana berusaha mengobati penyakitnya dengan memanfaatkan alam di sekitar.

(6) Jadi anak kayak, aduh mama sem perut sakit sekali aduh. Ini mag kah apa? Bawa ke rumah sakit kah? Ish rumah sakit jauh anak. Sudah ini pakai daun jati saja ini hei. Turun temurun begitu, akhirnya ob daun jati ini bagus untuk mag. Ternyata tidak juga sebenarnya. Karna orang tua malas saja antar kami ke rumah sakit. Jauh.

Data (6) mengungkapkan bagaimana masyarakat di sana menggunakan obat herbal dibandingkan dengan berobat ke rumah sakit. Implikatur konvensional yang terkandung dalam tuturan tersebut adalah jauhnya letak rumah sakit menyulitkan warga desa untuk berobat.

(7) Di tempat saya, flores timur, kabupaten flores timur, ibu kotanya larantuka. Itu Rumah sakitnya cuman satu. Namanya Rumah Sakit Umum Daerah Larantuka. Cuman satu itu. Tidak ada rumah sakit swasta lain. Rumah sakit cuman satu itu. Sedangkan kabupaten flores timur ini kabupaten yang terdiri dari pulau- pulau. Jadi orang dari pulau lain itu kalau mau ke rumah sakit, pakai kapal gitu. Nah sayaitu termasuk desa yang di pulau lain. Tidak berada dengan satu pulau dengan pulau flores. Jadi ketika di sanaitukarna adik saya yang anak keempat itu jadibidan. Dia itu sering cerita, sulit sekali ketika ada ibu-ibu yang mau melahirkan, yang mengalami pendarahan yang tidak bisa ditangani oleh bidan desa. Itu agak luar 
biasa itu, penanganannya itu. Jadi, Ibunya itu digotong sama suaminya, dengan bidannya itu, digotong pelan-pelan, dibawa ke atas perahu. Kemudian suaminya itu dengan siaganya gitu sambil dayung dia sambil menyemangati istrinya.

Data (7) merupakan kritikan kepada pemerintah dalam minimnya tenaga medis dan alat-alat kesehatan di desa tersebut. Kasus ibu-ibu yang akan melahirkan namun mengalami pendaharan harus segera ditangani oleh tenaga medis karena apabila pendarahannya banyak dan terlambat ditangani, dapat menyebabkan kematian.

Dalam lawakan Abdur pada data (7) tidak hanya mengandung kritikan terhadap pemerintah mengenai rumah sakit, tetapi juga diimplisitkan bahwa sarana transportasi di sana juga susah. Hal tersebut dilihat melalui pernyataan Abdur bahwa ibu yang akan melahirkan itu digendong oleh suaminya untuk diantarkan ke rumah sakit dengan menggunakan perahu. Jika penanganan yang dilakukan kepada ibu yang hendak melahirkan tersebut, dapat membahayakan nyawanya.

(8) Tidak jarang kasus yang, ya bukan kasus sih, kejadian yang terjadi di sana itu. Ibu melahirkan di atas perahu. Jadi ibu melahirkan, anaknya keluar, ambil dayung bantu bapaknya. "Semangat bapak, sedikit lagi. Ayo". Sampai rumahsakit,anaksudahSMP.

Data (8) memiliki punch line saat Abdur mengatakan bahwa ibu melahirkan di perahu, kemudian anaknya mengambil dayung untuk membantu Bapaknya dan menyemangati Bapaknya. Bagian tersebut memberikan efek lucu bagi penonton. Meskipun begitu, hal yang sebenarnya ingin disampaikan adalah saat darurat pun, transportasi yang ada hanyalah perahu. Untuk sampai ke Rumah Sakit yang jaraknya jauh dan tidak menempuh jalur darat, warga menggunakan perahu dayung. Akses ke rumah sakit yang sulit dan letak rumah sakit yang jauhlah yang diimplikasikan komika Abdur dalam lawakannya.

(9) Lumayan, yah. Sudah mulai memecah karbohidrat- karbohidrat tadi, ya. Lumayan lah. Karbohidratnya paling tidak dari beras yang bagus, bapak ibu semua. Saya itu karna lahir di sana, kemudian saya tidak dari keluarga yang tidak terlalu berada. Jadi, saya dari lahir, dari saya bisa makan lah, dari saya bisa makan, sampai saya SMA itu, keluarga saya sangat hobi makan beras miskin. RASKIN. Ada yang pernah makan raskin di sini? Tidak ada? Saya sendiri yang miskin di sini, ya? Oke. Orang kaya semua di sini ya.

Data (9) tersebut termasuk data yang mengandung implikatur konvensional bahwa ekonomi di desanya masih belum baik. Karbohidrat (beras) yang dikonsumsi sehari-hari tidaklah sebagus yang dikonsumsi oleh penonton. Penutur menyebutkan tentang raskin, hal tersebut mengandung makna yang diisyaratkan bahwa beras yang mereka terima melalui bantuan yang diberikan oleh pemerintah tidak seperti beras yang dikonsumsi oleh penonton. Dalam tuturannya ia juga menyinggung mengenai kaya dan miskin 
dengan mengatakanhanyaia orangmiskin di antara penonton yang hadir pada acara tersebut.

(10) Itu raskin itu murah sekali. Dia satu kilo cuman 1.700 rupiah per kilogram. Murah sekali. Tapi satu kilo kita beli, setengah kilonya itu kerikil. Saya tidak tau kenapa. Kalau saya baca di berita, diimpor dari Vietnam dan Thailand. Itu beras bagus sebenarnya. Tapi saya tidak tau apa yang terjadi di gudang bulog sampai ada kerikil masuk ke dalam. Kalau ada kutu, okelah. Kutu kan makhluk hidup, mungkin dia jalan- jalankan.Ini kerikil, kok bisa ada di dalam karung. Saya curiga karna dia saking murahnya, dia disantet sama pandan wangi dan beras ramos kayaknya.

Data (10) termasuk implikatur konvensional. Dalam lawakannya, Abdur tidak hanya memberikan informasi bahwa raskin itu murah dengan harga Rp 1.700 per kilogram, namun ia mengkritik dan menyindir hal tertentu. Ia mengkritik bahwa raskin yang dibeli dengan harga murah itu mengandung banyak kerikil. Ia juga dinilai menyindir bulog dengan kecurigaannya atas apa yang terjadi di gudang bulog hingga ada banyak kerikil didalam beras tersebut.

(11) Begitu berasnya bersih, kerikilnya kita bisa pakai untuk cor rumah.

Data (11) mengandung implikatur konvensional bahwa kerikil yang terdapat di dalam raskin itu dapat digunakan untuk cor rumah. Hal tersebut bermakna bahwa kerikil yang ada di dalam karung beras itu tidaklah sedikit.

\section{Implikatur Nonkonvensional}

Berdasarkan analisis yang dilakukan, lawakan Abdur pada acara Stand Up Comedy saat malam keakraban di Discovery Hotel, lawakan tersebut tidak mengandung implikatur nonkonvensional atau implikatur percakapan. Lawakan yang dituturkan oleh Abdur tanpa adanya percakapan lain dengan mitra tuturnya. Ia melakukan komunikasi dalam bentuk satu arah sehingga tidak terdapatimplikatur nonkonvensional atau implikatur percakapan dalam lawakan tersebut.

\section{KESIMPULAN}

Berdasarkan analisis daya yang dilakukan, dapat disimpulkan sebagai berikut. Pertama, terdapat implikatur dalam lawakan komika Abdur pada acara Stand Up Comedy. Kedua, terdapat 11 tuturan yang mengandung implikatur konvensional. Tuturan yang mengandung implikatur konvensional tersebut ada yang berupa kritikan dan sindiran. Secara umum, lawakan Abdur pada acara tersebut berkaitan dengan kritik dan keluhannya kepada pemerintah. Kritikan yang ia implisitkan dalam lawakannya berkaitan dengan sulitnya akses yang harus ditempuh untuk mendapatkan layanan kesehatan yang lebih baik. 
Daerahnya yang terdiriatas banyak pulau meenyulitkan mereka untuk berobat ke rumah sakit yang hanya ada 1 rumah sakit yang letaknya juga jauh. Ia juga dinilai mengkritik atas tidak layaknya raskin yang diterima oleh masyarakat di sana. Meskipun murah, ia heran bagaimana bisa kerikil masuk ke dalam karung beras raskin hingga bisa ia gunakan untuk mengecor rumah. Sementara itu, tidak terdapat implikatur nonkonvensional atau implikatur percakapan pada lawakan Abdur pada acara Stand Up Comedy.

\section{DAFTAR PUSTAKA}

Alfia, A. M., Rohmadi, M. \&Purwandi. (2014). Pelanggaran Prinsip Kesantunan dan Implikatur Percakapan dalam Acara Pas Mantab di Trans 7. Basastra, Jurnal Bahasa, Sastra, dan Pengajarannya,2(3), 1-8.

Andryanto, S. F., Andayani, \& Rohmadi, M. (2014). Analisis Pranggapan pada Percakapan Tayangan Sketsa di Trans TV. Basastra, Jurnal Bahasa, Sastra, dan Pengajarannya, 2(3), 1-16.

Budiyanto, D. (2009). Penyimpangan Implikatur Percakapan dalam Humorhumor Gus Dur. Litera, JumalPenelitian Bahasa, Sastra, dan Pengajarannya, 8(2), $105-117$

Handayani, C., Sumawarti, \& Suhita, R. (2014). Implikatur Percakapan dalam Acara Talk Show Mata Najwa di Metro TV. Basastra, Jurnal Babasa, Sastra, dan Pengajarannya, 2(3), 1-14.

Hasanah, N. (2017). Makalah disajikan pada Seminar Nasional II (Pemartabatan Babasa Indonesia Melalui Budaya Literasi dan Optimalisasi (IPTEKS): Implikatur dalam Lawakan Abdur pada Acara Stand Up Comedy di Kompas TV (Kajian Pragmatik, Universitas PGRI Semarang, Semarang, Indonesia. Hal 170176.

Irnanda, I. N. \& Hamzah. (2017). Conversational Implicature as Found in Buyers' and Sellers' Interaction in the Traditional Market of Lubuk Alung. JELL, E- Journal of English Language \& Literature, 6(2).

Lubis, I. S. (2015). Conversational Implicatures of Indonesia Lanyers Club Program on TV One . CaLLs: Journals of Culture, Arts, Literature, and Linguistics, 1(2), Hal3244.

Nugraheni, Y. (2011). Implikatur Percakapan Tokoh Wanita dan Tokoh Laki-laki dalam Film Harry Potter and The Goblet of Fire. Lensa: Kajian Kebahasaan, Kesusastraan, dan Budaya, 1(2), 183-193.

Nugraheni, Y. (2010). Makalah disajikan pada Seminar Nasional UNIMUS: Analisis Implikatur pada Naskab Film Harry Potter and the Goblet of Fire, Universitas Muhammadiyah Semarang, Indonesia. Hal 390-397.

Nurifa, N., Tressyalina, T., \& Noveria, E. (2018). Tindak Tutur Langsung dan Tidak Langsung Guru dalam Mata Pelajaran Bahasa Indonesia di Kelas XI SMA Adabiah Padang. Pendidikan Bahasa Indonesia, 7(3), 241- 
248.

Rosyida, F \& Asror, A.G. (2019). Makalah disajikan pada Seminar Nasional UNIMUS: Implikatur pada Iklan Politik Calon Anggota Legislatif Kabupaten Bojonegoro 2019, IKIP PGRI Bojonegoro, Bojonegoro, Indonesia. Hal 181-185.

Sari, P \& Litbagay, A. J. (2019). Implicature in the Dialogue of 500 Days of Summer Movie by Marc Webb: the Study of Pragmatics. Eljutama: English Journal Literacy Utama, 3(1), Hal 35-39.

Wahyuningsih, H. \& Rafli, Z. (2017). Implikatur Percakapan dalam Stand Up Comedy 4. Babtera, Jurnal Pendidikan Bahasa dan Sastra, 16(2), 139-153.

Wijayanti, A. (2016). Presuposisi dan Implikatur pada Stand Up Comedy Indonesia. Transformatika, Jurnal Bahasa, Sastra, dan Pengajarannya, 12(2), 46-59.

Yule,

G.

(1993).

Pragmatics.

from

http://id.scribd.com/doc/11637500/YuleGeorge-Pragmatics 